\section{Adalimumab in Crohn's strictures-the CREOLE study}

We compliment the authors of the CREOLE study ${ }^{1}$ evaluating the efficacy of adalimumab in patients with Crohn's disease and symptomatic small bowel stricture. That about two-thirds of patients responded at 24 weeks and about a third of the symptomatic patients were able to avoid surgery at 4 years is impressive. The authors also need to be complimented for attempting to develop a predictive model.

A typographical error seems to have unfortunately crept into their manuscript. Table 3 mentions the length of the strictures on MRI in millimetres, when they probably meant centimetres.

Three of the ninety-seven patients in this study had L2 disease; the inclusion criteria were restricted to patients with small bowel strictures. Did these patients have colonic strictures as well? Would the symptoms then not be misleading?

Crohn's disease obstructive score is a tool based on the experience of the authors and needs validation. It is subjective and difficult to use. Especially grade 3, which suggests different severity of obstructive pain. It needs modification to a simpler grading system such as mild, moderate (associated symptoms and dietary restriction) and severe. Only two small earlier studies have looked into the effect of biologics (infliximab) on strictures in Crohn's disease. ${ }^{2}{ }^{3}$ It would therefore be interesting to know the outcome of the 35 patients in this study who received infliximab.

If the results from the CREOLE study are reproduced in more randomised controlled trials, it will have significant impact on decision-making in these patients.

Ajinkya Ashok Sonambekar, Devendra C Desai, Anand Joshi, Pavan Dhoble

Division of Gastroenterology, P. D. Hinduja National Hospital, Mumbai, India

Correspondence to Dr Ajinkya Sonambekar, P. D. Hinduja National Hospital, Mahim, Mumbai 400016, India; ajinkya.sonambekar@gmail.com

Contributors All authors have contributed equally to the manuscript.

Competing interests None declared.

Provenance and peer review Not commissioned; internally peer reviewed.

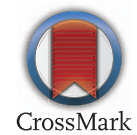

To cite Sonambekar AA, Desai DC, Joshi A, et al. Gut 2018;67:198.

Revised 14 March 2017

Accepted 16 March 2017

Published Online First 5 April 2017

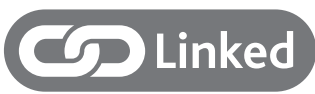

http://dx.doi.org/10.1136/gutjnl-2016-312581

http://dx.doi.org/10.1136/gutjnl-2017-314431

Gut 2018;67:198. doi:10.1136/gutjnl-2017-314124

\section{REFERENCES}

1 Bouhnik Y, Carbonnel F, Laharie D, et al. Efficacy of adalimumab in patients with Crohn's disease and symptomatic small bowel stricture: a multicentre, prospective, observational cohort (CREOLE) study. Gut 2018;67:53-60.

2 Pallotta N, Barberani F, Hassan NA, et al. Effect of infliximab on small bowel stenoses in patients with Crohn's disease. World I Gastroenterol 2008;14:1885-90.

3 Pelletier AL, Kalisazan B, Wienckiewicz J, et al. Infliximab treatment for symptomatic Crohn's disease strictures. Aliment Pharmacol Ther 2009;29:279-85. 